\title{
Optimal Fiscal Policy with Rationing in the Labor Market
}

\author{
Arantza Gorostiaga \\ CEMFI and Universidad Complutense
}

Working Paper No. 9908

July 1999

I would like to thank Albert Marcet for his suggestions and guidance. I am also indebted to Manuel Balmaseda, Samuel Bentolila, Jorge Blázquez, J. Ignacio García, Omar Licandro and a seminar audience at CEMFI. Of course, all remaining errors are my own. (E-mail: arantza@cemfi.es).

CEMFI, Casado del Alisal 5, 28014 Madrid, Spain.

Tel: 3491 4290551, fax: 3491 4291056, www.cemfi.es. 


\begin{abstract}
This paper characterizes the optimal fiscal policy when it is assumed that there exists a minimum wage below which no worker can be hired. The rigidity due to the minimum wage legislation can lead to equilibria in which the supply side of the labor market is rationed. One of the main results of the paper is that allocations in which the worker is involuntarily unemployed can be found to be optimal. The main conclusion with respect to the stabilizing properties of the optimal policy is that it should not be used to offset the negative effects of the cycle in the economy.
\end{abstract}




\section{Introduction}

There seems to be a quite widespread agreement among macroeconomists that one of the main contributions of Real Business Cycle (RBC) models is a methodological one. This literature has developed quantitative and dynamic models in which agents' objectives and constraints are explicitly considered. The standard RBC model has been criticized because it cannot account for some desirable properties. Many authors have noted some features of these models that make them skeptical about the applicability of the results. One of these criticisms is that RBC models abstract from all sort of market failures like externalities, problems with information and incentives or non-price-taking behavior. However, the basic theoretical framework is flexible enough to articulate different views including those mentioned above. Recent research has been able to rationalize ideas that were the core of macroeconomics before the 1970s by incorporating a variety of frictions into the standard RBC model.

This paper aims to move in this direction. Our goal is to analyze the properties of the optimal fiscal policy when a labor market with frictions is assumed. More precisely, we will assume that an institution sets a minimum wage taken as exogenously given by all agents in our economy. We build a dynamic general equilibrium model that allows us to merge two distinguished traditions in economics: the public finance tradition and the disequilibrium literature. The public finance literature we are referring to is that applying Ramsey's (1927) formulation to analyze fiscal policy over time. A number of articles have adopted this approach that characterize the optimal policy as that maximizing the welfare of the economy. Major contributions are the 
articles by Lucas and Stokey (1983) and Chari, Christiano and Kehoe (1994).

The key to the disequilibrium theory is the premise of a system of markets which are not always cleared and that may imply the existence of rationed individuals. Contributions by Patinkin (1965), Clower (1965) and Barro and Grossman (1971) represent the pioneering work in macroeconomic disequilibrium theory. The basic model introduced by these authors has been further examined and extended by a number of theoretical papers (for example Benassy (1975), Malinvaud (1977), Hahn (1978), and Neary and Stiglitz (1983), to name a few).

In this paper we consider a stochastic economy with three infinitely lived agents: consumers, firms and the government. ${ }^{1}$ The minimum wage assumption implies a constraint for the labor supply. The firm will not be willing to hire more labor than the quantity implied by its inverse labor demand. As a result, the budget constraint will no longer be the only restriction faced by the household when making decisions about consumption and leisure. Now, the consumer takes into account that he is also bound by the constraint implied by the minimum wage and he will not be able to sell more labor input than that demanded by the firm when this constraint is binding. Hence, the rigidity in the labor market due to the minimum wage can lead to equilibria in which the supply side is rationed and involuntary unemployment arises. When the literature of fixed-price has studied general disequilibrium models it has distinguished between two different concepts of demand and/or supply: the notional and the effective demand (supply). The notional supply

\footnotetext{
${ }^{1}$ The basic theoretical framework is Lucas and Stokey's (1983) including also the assumptions introduced by Gorostiaga (1999).
} 
schedule shows the amount of labor the consumer would like to sell if he were not constrained; the effective supply shows the amount of labor he actually can sell given the demand-side restrictions. We talk about involuntary unemployment in the sense that the labor equilibrium allocation is different from the notional supply. ${ }^{2}$

The government is assumed to be a Ramsey planner who decides the optimal fiscal policy maximizing the consumer's utility. The decision variables of the government are: public spending, the labor income tax rate and debt issues. We assume that bonds are state contingent and there are complete markets for debt. We compute the full-commitment solution. If the government could reoptimize in the future, it would do something different from what it had promised to do and the solution would be time-inconsistent.

The computational issues associated with the finding of the equilibrium stochastic processes are a crucial element of our work. To our knowledge, there is no article in disequilibrium theory analyzing the fiscal policy that results from a Ramsey problem in a dynamic economy with rational expectations. Presumably, the reason is the nature of the problem, which includes inequality constraints and non-linearities that make the model difficult to solve. In order to compute the equilibrium paths for the endogenous variables we perform numerical simulation exercises.

One of the main results of the paper is that allocations in which the worker is involuntarily unemployed can be found to be optimal. This outcome is caused by high minimum wages that imply large distortions and a small

\footnotetext{
${ }^{2}$ There is no consensus on what an involuntarily unemployed worker is. Our definition agrees with that suggested by Pissarides (1988).
} 
scope for government intervention. Moreover, the minimum wage legislation leads to welfare losses, which are larger the higher the exogenous minimum wage. The main conclusion with respect to the stabilizing properties of the optimal policy is that it should not be used to offset the negative effects of the cycle in the economy. We find that government spending should be higher and the labor income tax rate should be smaller in good times than in bad times.

The article is organized as follows. In section 2 we set the theoretical framework underlying the analysis. Section 3 outlines the simulation procedure and analyzes the results. Finally, section 4 concludes.

\section{The Minimum-Wage Model}

We consider a production economy with three infinitely-lived agents: a representative consumer, a firm, and the government. There is a private consumption good $\left(c_{t}\right)$ and a public good $\left(g_{t}\right)$ that satisfy

$$
c_{t}+g_{t}=y_{t}
$$

$y_{t}$ being aggregate output.

We consider a constant returns to scale concave production function:

$$
y_{t}=f\left(\theta_{t} ; 1-x_{t}, \ell_{t}\right)
$$

where $x_{t}$ denotes leisure, $\ell_{t}$ is land and $\theta_{t}$ is a productivity shock following a Markov process: 


$$
\ln \theta_{t}=\rho \ln \theta_{t-1}+\varepsilon_{t}, \quad|\rho|<1, \quad \varepsilon_{t} \sim N\left(0, \sigma_{\varepsilon}^{2}\right)
$$

being this technology shock the only source of uncertainty in our economy.

The consumer derives utility from private consumption, public spending and leisure. The household's preferences are given by the von NeumannMorgenstern utility function:

$$
E_{0} \sum_{t=0}^{\infty} \beta^{t} u\left(c_{t}, g_{t}, x_{t}\right), \quad 0<\beta<1
$$

The utility function $u$ is strictly increasing in the three arguments and strictly concave. Private consumption, government expenditures and leisure are normal (non-inferior). $E_{0}$ denotes the mathematical expectation conditioned on time 0 information.

The representative consumer is endowed with one unit of time which is devoted to work and leisure. He also owns $\bar{\ell}$ units of land that will be inelastically supplied to the firm. Besides, the household can lend to or borrow from the government with a full array of contingent one-period bonds that complete the markets.

The consumer faces the following budget constraint:

$$
c_{t}+\int p_{t}^{b}(\theta) b_{t}(\theta) d \theta=\left(1-\tau_{t}\right) w_{t}\left(1-x_{t}\right)+b_{t-1}\left(\theta_{t}\right)+p_{t}^{\ell} \ell_{t}
$$

where $\tau_{t}$ is the income tax rate, $w_{t}$ the wage rate and $p_{t}^{\ell}$ is the land price. $p_{t}^{b}(\theta)$ denotes the price the consumer has to pay in period $t$ to get one unit of consumption good at $t+1$ if the productivity shock realization is $\theta$ at this time and $b_{t}(\theta)$ is the number of units of debt (contingent on $\theta$ ) held in period $t$. We assume that the consumer is a price taker in all the markets. The 
household's problem is to choose $^{3}\left\{c_{t}^{d}, x_{t}^{s}, \ell_{t}^{s}, b_{t}^{d}\right\}$ maximizing the discounted sum of utilities given by (4) subject to the temporal sequence of budget constraints (5). Besides, his labor supply must be smaller than the perceived constraint $^{4} \overline{S C_{t}}$, a quantity he takes as given. We can write the program as follows:

$$
\max _{\left\{c_{t}^{d}, x_{t}^{s}, \ell_{t}^{s}, b_{t}^{d}\right\}} E_{0} \sum_{t=0}^{\infty} \beta^{t} u\left(c_{t}^{d}, g_{t}, x_{t}^{s}\right)
$$

subject to:

$$
\begin{aligned}
& c_{t}^{d}+\int p_{t}^{b} b_{t}^{d}(\theta) d \theta=\left(1-\tau_{t}\right) w_{t}\left(1-x_{t}^{s}\right)+b_{t-1}^{d}\left(\theta_{t}\right)+p_{t}^{\ell} \ell_{t}^{s} \\
&\left(1-x_{t}^{s}\right) \leq \overline{S C_{t}} \\
& \ell_{t}^{s} \leq \bar{\ell} \\
&\left\{\tau_{t}, \theta_{t}, p_{t}^{b}(\theta), p_{t}^{\ell}, w_{t}, g_{t}, b_{t-1}^{d}\left(\theta_{t}\right), \overline{S C_{t}}\right\} \text { as given }
\end{aligned}
$$

Using the Kuhn-Tucker theorem, the first order conditions we find are:

$$
\begin{aligned}
p_{t}^{b}(\theta) & =\beta \frac{u_{c, t+1}(\theta)}{u_{c, t}} \operatorname{Pr}\left(\theta_{t+1}=\theta / \theta_{t}\right) \\
\tau_{t} & =1-\frac{u_{x, t}+\nu_{1, t}}{w_{t} u_{c, t}} \\
\nu_{1, t}\left[\overline{S C_{t}}\right. & \left.-\left(1-x_{t}^{s}\right)\right]=0 \\
\overline{S C_{t}} & \geq\left(1-x_{t}^{s}\right) \quad \nu_{1, t} \geq 0
\end{aligned}
$$

\footnotetext{
${ }^{3}$ We use the superscripts $d$ and $s$ to distinguish between demanded and supplied quantities. Variables without any superscript refer to equilibrium quantities.

${ }^{4}$ The worker faces this constraint because he will not be able to sell more labor than that demanded by the firm when the minimum wage constraint is binding.
} 
where $\nu_{1, t}$ is the Lagrange multiplier associated with inequality (7). Besides, the worker supplies inelastically his endowment of land.

The firm maximizes its profits taking the input prices as given. In other words, the firm's problem is:

$$
\begin{gathered}
\max _{\left\{x_{t}^{d}, \ell_{t}^{d}\right\}} y_{t}-w_{t}\left(1-x_{t}^{d}\right)-p_{t}^{\ell} \ell_{t}^{d} \\
\left\{\theta_{t}, w_{t}, p_{t}^{\ell}\right\} \text { as given }
\end{gathered}
$$

The solution to the problem of the firm implies that input inverse demands equal the corresponding marginal productivity, that is,

$$
\begin{aligned}
w_{t}(\cdot) & \equiv f_{1-x}\left(\theta_{t} ; \cdot, \ell_{t}^{d}\right) \\
p_{t}^{\ell}(\cdot) & \equiv f_{\ell}\left(\theta_{t} ; 1-x_{t}^{d}, .\right)
\end{aligned}
$$

where $f_{1-x}$ and $f_{\ell}$ are the derivatives of the production function with respect to labor and land respectively. ${ }^{5}$

We assume that there is an institution that sets a minimum wage $w_{M I N}$ below which the firm cannot hire any labor. This variable is taken as exogenously given by all agents in our economy. This is a new assumption with respect to the previous literature in which competitive labor markets have been mostly assumed. As far as we know, the only paper solving for the optimal fiscal policy and introducing frictions in the labor market is Gorostiaga (1999) where it is assumed that a union sets wages. The minimum wage assumption only constrains the labor supply because the firm will not hire

\footnotetext{
${ }^{5}$ In what follows, we will assume that $\bar{\ell}$ is equal to one and we will not consider explicitly this variable anymore.
} 
more labor than its demand at each period. ${ }^{6}$ Thus, equilibria in which the worker is rationed in the labor market may arise in this framework.

The government is assumed to be a Ramsey planner that decides the optimal fiscal policy maximizing the household's objective function. It provides the public good and funds its spending by labor income taxes and debt. At each period, the public sector faces the following budget constraint:

$$
g_{t}+b_{t-1}^{s}\left(\theta_{t}\right)=\left(1-\tau_{t}\right) w_{t}\left(1-x_{t}\right)+\int p_{t}^{b} b_{t}^{s}(\theta) d \theta
$$

The government announces the public policy it is going to implement and the consumer takes these policies as given. The government is aware of this reaction and includes the first order conditions of the household's and the firm's problems as constraints in its own maximization problem. In other words, the government chooses the optimal policy among the minimum-wage equilibrium allocations characterized by the following definition.

Definition 1: Given $b_{-1}, w_{M I N}$ and the productivity shock process $\left\{\theta_{t}\right\}$, a minimum-wage equilibrium is a stochastic process of prices $\left\{p_{t}^{b}(\theta), w_{t}, p_{t}^{\ell}\right\}$, perceived constraint $\overline{S_{t}}$, allocations $\left\{c_{t}, b_{t}, x_{t}, \ell_{t}\right\}$ and fiscal policy $\left\{g_{t}, \tau_{t}, b_{t}\right\}$ such that:

i) $\left\{c_{t}, b_{t}, x_{t}, \ell_{t}\right\}$ maximizes the consumer's objective function (4) subject to the budget constraints (5) and the restriction implied by $\overline{S C_{t}}$ and taking as given $\left\{p_{t}(\theta), w_{t}, p_{t}^{\ell}\right\}$ and $\left\{g_{t}, \tau_{t}\right\}$.

ii) $\left\{x_{t}, \ell_{t}\right\}$ maximizes the firm's profits given $\left\{w_{t}, p_{t}^{\ell}\right\}$.

\footnotetext{
${ }^{6}$ The labor equilibrium allocation will be always on the labor demand schedule but the only feasible allocations will be those points above the corresponding to the minimum wage one.
} 
iii) The equilibrium wage $w_{t}$ is equal to or higher than the exogenous bound $w_{M I N}$

$i v$ ) The government budget constraint (13) and the economy's technology constraint (1) are satisfied at each period.

$v$ ) The land, consumption goods and bonds markets clear.

It is straightforward that allocations satisfying restrictions (10)-(12) can be characterized by the following inequality:

$$
\tau_{t} \leq 1-\frac{u_{x, t}}{w_{t} u_{c, t}}
$$

Using standard arguments, we can prove $^{7}$ that the restriction that (9) and (13) place on Ramsey equilibrium allocations is characterized by the implementability constraint: ${ }^{8}$

$$
b_{-1}=E_{0} \sum_{t=0}^{\infty} \beta^{t} \frac{u_{c, t}}{u_{c, 0}}\left[\tau_{t} w_{t}\left(1-x_{t}\right)-g_{t}\right]
$$

That is, the present value of outstanding government obligations at time 0 must equal the present value of the excesses of tax revenues over government expenditures on goods.

\footnotetext{
${ }^{7} \mathrm{~A}$ formal proposition and proof showing this result can be found in Chari and Kehoe (1998).

${ }^{8} \mathrm{We}$ assume that there are high enough debt limits to prevent the possibility of a Ponzi game. As a result, the following transversality constraint is fulfilled:

$$
\lim _{T \rightarrow \infty} E_{t}\left[\beta^{T+1} \frac{u_{c, T+1}}{u_{c, 0}} b_{T+1}\right]=0
$$
}


Therefore, we can write the Lagrangian for the Ramsey problem as

$$
\begin{aligned}
L= & E_{0} \sum_{t=0}^{\infty} \beta^{t} u\left[\theta_{t}\left(1-x_{t}\right)^{\gamma}-g_{t}, g_{t}, x_{t}\right] \\
& +\lambda\left[b_{-1} u_{c, 0}-E_{0} \sum_{t=0}^{\infty} \beta^{t} u_{c, t}\left[w_{t} \tau_{t}\left(1-x_{t}\right)-g_{t}\right]\right] \\
& +\sum_{t=0}^{\infty} \beta^{t}\left[\delta_{t}\left(w_{M I N}-w_{t}\right)+\mu_{t}\left(u_{x, t}-\left(1-\tau_{t}\right) w_{t} u_{c, t}\right)\right]
\end{aligned}
$$

where $w_{t}$ should be equal to the inverse labor demand $w_{t}($.$) .$

Taking derivatives with respect to government expenditures $\left(g_{t}\right)$, leisure $\left(x_{t}\right)$ and the labor-income tax $\left(\tau_{t}\right)$ we get the first order conditions ${ }^{9}$

$$
\begin{aligned}
-u_{c, t} f_{1-x, t}+u_{x, t}+\lambda \Lambda_{1, t}+\delta_{t} \Lambda_{2, t}+\mu_{t} \Lambda_{3, t} & =0 \\
-u_{c, t}+u_{g, t}+\lambda \Psi_{1, t}+\mu_{t} \Psi_{2, t} & =0 \\
\lambda\left(1-x_{t}\right) & =\mu_{t}
\end{aligned}
$$

If an optimal policy exists and the solution is interior, this policy must satisfy the first order conditions jointly with the implementability constraint

${ }^{9}$ where

$$
\begin{aligned}
\Lambda_{1, t} & =u_{c c, t} f_{1-x, t}\left[f_{1-x, t} \tau_{t}\left(1-x_{t}\right)-g_{t}\right]+u_{c, t} \gamma f_{1-x, t} \tau_{t} \\
\Lambda_{2, t} & =f_{1-x 1-x, t} \\
\Lambda_{3, t} & =u_{x x, t}+\left(1-\tau_{t}\right) u_{c c, t}\left(f_{1-x, t}\right)^{2}+\left(1-\tau_{t}\right) f_{1-x 1-x, t} u_{c, t} \\
\Psi_{1, t} & =u_{c, t}+\left(u_{c c, t}-u_{c g, t}\right)\left[f_{1-x, t} \tau_{t}\left(1-x_{t}\right)-g_{t}\right] \\
\Psi_{2, t} & =\left(1-\tau_{t}\right) f_{1-x, t}\left(u_{c c, t}-u_{c g, t}\right)
\end{aligned}
$$


and the resource constraint. We can prove that the endogenous variables of the model can be written as time invariant functions of the contemporaneous productivity shock and the Lagrange multiplier $\lambda$, that is,

$$
\left(c_{t}, x_{t}, g_{t}, \tau_{t}, p_{t}, b_{t}\right)=d\left(\lambda, \theta_{t}\right)
$$

The obtained first order conditions are quite similar to those found in previous papers like Lucas and Stokey (1983) except for equation (18). This additional expression arises due to the possibility of finding rationed agents in the economy. It is worth explaining the implications of this new condition. When the labor supply is constrained in one period, the optimal labor allocation is equal to the demand of the firm which is the short side of the market. Taking into account the resource constraint (1), the social planner only has to decide how much output should be delivered as public services. The government will choose its level of spending so as to equate the marginal utility of private and public consumption. In this period the way used by the government to fund its expenses does not change the equilibrium allocations. As a result, the public sector can set higher taxes when the labor supply is constrained and reduce these taxes in good times. By implementing this policy, the government will be able to reach the first best allocation when the economy is booming. Equation (18) allows us to analyze this result more formally. When the labor supply is constrained, the multiplier $\mu_{t}$ is equal to zero. ${ }^{10}$ Substituting into (18), the Lagrange multiplier $(\lambda)$ associated with the implementability constraint is also equal to zero. This implies that the funding of the public spending is not constraining the decisions taken by the

\footnotetext{
${ }^{10}$ Note that $\mu_{t}$ is the multiplier associated with inequality (14) which is not exactly the constraint faced by the consumer in the labor market, i.e. (7).
} 
agents in the economy and that we do not have to take into account the intertemporal government budget constraint when solving for the optimal allocations.

\section{$3 \quad$ Numerical results}

We aim to analyze how the equilibrium allocations for the endogenous variables evolve over the business cycle. Therefore, we have to solve the system of equations presented in the preceding subsection.

We specify functional forms for both, production function and preferences. We assume a Cobb-Douglas technology showing constant returns to scale:

$$
f\left(\theta_{t} ; 1-x_{t}, \ell_{t}\right)=\theta_{t}\left(1-x_{t}\right)^{\gamma} \ell_{t}^{1-\gamma} \quad 0<\gamma<1
$$

and the following functional form for the preferences:

$$
u\left(c_{t}, g_{t}, x_{t}\right)=\frac{\left[c_{t}^{\alpha} g_{t}^{1-\alpha}\right]^{1-\sigma_{1}}}{1-\sigma_{1}}+\frac{x_{t}^{1-\sigma_{2}}}{1-\sigma_{2}} \quad 0<\alpha<1
$$

This utility function is additively separable in consumption and leisure. We are considering a composite consumption index which includes both the privately and the publicly provided good.

The first order conditions are non-linear functions of the endogenous variables. Due to these strong non-linearities there is no way of obtaining closed form solutions to the model. Furthermore, decision rules depend not only on $\theta_{t}$ but also on the unobservable shadow price $\lambda$. Taking $\lambda$ as given like in Lucas and Stokey (1983), we could study the sign of the derivative of the 
endogenous variables with respect to the shock. However, we are also interested in studying the switch from one rationing scheme to another, caused by different technological shocks. This analysis requires the computation of the equilibrium paths because simple derivatives say nothing about these changes. These facts lead to the need for numerical simulations.

In order to find the equilibrium solutions for both models we have to specify values for the parameters appearing in them. The values we have chosen are presented in Table 1 . We have not performed a calibration exercise, we have just selected values for the parameters that are standard in the RBC literature.

Table 1: Parameter Values

\begin{tabular}{||cc||}
\hline \hline Preferences & \\
\hline$\beta$ & 0.95 \\
$\alpha$ & 0.8 \\
$\sigma_{1}$ & 3 \\
$\sigma_{2}$ & 2 \\
\hline \hline Production Function \\
\hline \hline \multicolumn{2}{||c||}{} \\
\hline \hline Technology Shock \\
\hline \hline$\sigma_{\varepsilon}$ & 0.66 \\
\hline \hline
\end{tabular}

We also have to specify a value for the minimum wage, $w_{M I N}$. It has been empirically observed that workers devote to leisure two thirds of their time endowment. We get this result for the allocation of leisure in the steady state 
when we assume that the minimum wage is equal to 0.20 . We have solved the model for different values around this figure. The procedure followed to simulate the equilibrium paths for the endogenous variables is described in the appendix.

We present our results graphically plotting the decision rules $d(\lambda, \cdot)$. Figure 1 shows these graphs $w_{M I N}=0.17$ and $w_{M I N}=0.20$. We should notice that the choice of the value for $w_{M I N}$ is important because depending on this value, the rationing scheme observed in equilibrium may be different. Before analyzing the cyclical properties of the endogenous variables, we will try to figure out the intuition behind the optimal policy implemented by the government.

The two figures below will help us to understand what is going on. These graphs show the pattern observed for leisure in the two possible cases: when $\mu_{t}$ is strictly negative and when it is equal to zero.

The Ramsey planner chooses the optimal fiscal policy maximizing the consumer's objective function. Since the economic welfare will be smaller if the consumer is constrained in the labor market, the government will try to avoid this situation. The social planner will move the labor supply through taxation in order to prevent non-desirable rationing schemes. During recessions the technological shock is small and so is the marginal productivity of labor. The notional demand is not likely to be as high as the notional supply and the labor equilibrium allocation will be determined by the demand side of the market. In other words, involuntary unemployment arises in bad times. Besides, the larger the minimum wage is, the higher the probability of labor demand determined equilibria in bad times. Hence, if the govern- 
ment wants to avoid involuntary unemployment it will have to increase taxes and reduce the labor supply during recessions. If the minimum wage is very high, the labor demand is small and the increase in taxes required to equate the labor supply and the labor demand should be too large. It is not worth introducing such a big distortion in order to prevent households from being rationed in bad times. Therefore, we will find that the constraint faced by the labor supply will be binding and the corresponding Kuhn-Tucker multiplier, $\mu_{t}$, will be zero. Moreover, the implementability constraint will no longer be a binding restriction in the Ramsey problem $(\lambda=0)$. During recessions, the labor supply is constrained and the equilibrium allocations of private consumption, government spending and leisure do not depend on the fiscal policy implemented by the public sector. ${ }^{11}$ Therefore, the government can increase both the labor income tax rate and tax revenues without affecting equilibrium allocations. Being aware of this, the Ramsey planner will set higher taxes during bad times and it will be able to reach the first best allocation when the technological shock is larger. When the minimum wage is not so high, the government will not find best to implement the fiscal policy we have just described. In this case, during recessions the planner will set higher taxes in order to reduce the labor supply and reach an equilibrium allocation in which none of the agents is constrained in the labor market.

During good times, or more precisely when the technological shock is sufficiently high, the optimal scheme is the same no matter how large the

\footnotetext{
${ }^{11}$ The labor allocation will be equal to the notional demand. And private consumption and government spending will be such that the last unit of private consumption renders the same utility as the last unit of public good.
} 
minimum wage is. For these states of nature, the marginal productivity of labor is high and the firm is willing to pay a wage higher than the minimum wage $w_{M I N}$. As a result, labor demand will be equal to labor supply and no sides of the labor market will be rationed in equilibrium.

Figure 1 displays the decision rules $d(\lambda, \cdot)$, that is, it plots the technological shock versus the endogenous variables. These graphs show the correlation between the variables and can be used to study their cyclical properties. All the lines depicted exhibit a kink at some value of the productivity shock. For realizations of the technology shock below this value, the minimum wage restriction is binding. Moreover, the kink moves to the right when $w_{M I N}$ is larger. That is, the higher the minimum wage the firm has to pay, the higher the productivity shock has to be in order to obtain a notional labor supply not larger than the labor demand.

In both cases, when $\mu_{t}$ is strictly negative and when this variable equals zero, we can draw the same conclusions about how the private and public consumption and leisure evolve over the cycle. Both private consumption and public services are procyclical variables in the sense that they are positively correlated with output. Therefore, the public sector does not use its expenditure to stabilize output. The slope of the depicted lines is bigger during bad times. Hence, although government spending is procyclical, public policy is more active during recessions.

Leisure decreases with the productivity shock during bad times but shows a positive reaction when the economy is booming. The possibility of labor demand determined equilibria when the technological variable is small results in this pattern for leisure. During recessions, the labor allocation is always 
equal to the labor demand. The marginal productivity of labor, and therefore, labor demand is higher when the technological shock is larger. Hence, the equilibrium leisure allocation will decrease with the productivity shock in bad times. Conversely, when the economy is booming, the labor equilibrium allocation is such that labor demand equals labor supply. Since the consumer derives utility from leisure and the wealth effect is larger than the substitution effect in good times, the labor allocation will be smaller the larger the productivity shock.

The results for the labor income tax rate are different depending on the size of the minimum wage. For small minimum wages, optimal labor income tax rates will decrease with the technological shock, that is, they should be smaller when the economy is booming. The reason for this downward sloping pattern is that in good times it is not worth distorting economic decisions with higher tax rates. When the minimum wage is high and the labor supply is constrained during recessions, we can find multiple equilibrium solutions for the labor-income tax satisfying the government intertemporal budget constraint. To some extent, we can say that a sort of Ricardian equivalence holds. Figure 1 shows one of these solutions. In bad times, optimal allocations can be implemented no matter the size of the labor income tax rates. Thus, the planner will set very high taxes during recessions and will be able to reach the first best allocations removing these taxes in good times.

This analysis also allows us to study the implications for welfare of changes in the minimum wage. A higher minimum wage increases distortions which have adverse effects on the efficiency of the economy. If we compute the sum of discounted utilities both when the minimum wage is 0.17 and 0.2 , we find 
that this sum is -0.57 in the first case and -0.72 in the second one. When the minimum wage is high, the scope for the government to be close to the first best is smaller. Although the first best allocations are attained in good times, the large distortions during recessions lead to an important welfare loss.

To sum up, involuntary unemployment and welfare losses arise, caused by the assumption of a minimum wage legislation. These effects are stronger the higher the minimum wage level. Another remarkable result is that the government should not use the fiscal policy to stabilize output. However, since rationing in the supply side of the labor market is not a desirable situation, the fiscal policy will be much more active when this rationing scheme prevails.

\section{Concluding Remarks}

This paper has studied the implications for the optimal fiscal policy of including a minimum wage in a standard public finance model. We find that fiscal policy should not be used to stabilize output. Contrary to what we may expect, government spending should be higher and the labor income tax rate should be smaller in good times than in bad times. Besides, the minimum wage legislation leads to the possibility of finding rationed agents in our economy. More precisely, we find equilibria with rationed workers or, in other words, involuntary unemployment during recessions. Moreover, the rigidity assumed in the labor market results in welfare losses which are larger the higher the minimum wage. 
However, the point we want to stress is that the framework that we have presented is flexible enough to analyze the optimal policy in an economy with frictions. The basic theoretical model is very simple and abstracts from many issues we would like to include in a model meant to be used to derive economic policy recommendations. Nevertheless, the methodology we are using is the proper one: we have studied a dynamic rational expectations model and we have been precise about agent's preferences and constraints, technology and how agents take decisions. Including other rigidities, assuming different sources of uncertainty and/or considering heterogenous agents are the goal of future extensions. Moreover, this paper may be a first step to new research within the disequilibrium literature. Ideas analyzed in the 70s by the authors mentioned in the introduction can also be studied using the methodology of the RBC models. This seems to be a very interesting research to carry out in the future. 


\section{Appendix}

This appendix describes the procedure we have used to compute the equilibrium paths for the endogenous variables. We have to solve a system of equations that includes the first order conditions (16)-(18), the resource constraint (1), the implementability constraint (15) and the following inequalities resulting from the Kuhn-Tucker formulation:

$$
\begin{aligned}
\delta_{t}\left[w_{M I N}-w_{t}\right] & =0 \\
\mu_{t}\left[u_{x t}-\left(1-\tau_{t}\right) w_{t} u_{c t}\right] & =0
\end{aligned}
$$

$$
\begin{aligned}
\delta_{t} \leq 0 & w_{M I N} \leq w_{t} \\
\mu_{t} \leq 0 & u_{x t}-\left(1-\tau_{t}\right) w_{t} u_{c t} \leq 0
\end{aligned}
$$

We consider four possible cases:

Case 1: $\mu_{t}=0 \quad \delta_{t}=0$

Case 2: $\mu_{t}=0 \quad \delta_{t} \leq 0$

Case 3: $\mu_{t} \leq 0 \quad \delta_{t}=0$

Case 4: $\mu_{t} \leq 0 \quad \delta_{t} \leq 0$

We study cases 1-2 and cases 3-4 separately. The reason is that from equation (18) we know that if the multiplier $\mu$ is zero in the first period, it will be zero forever. The same applies when this multiplier is negative. $\mu_{0}$ will depend on the initial technology shock, $\theta_{0}$, and the minimum wage, $w_{M I N}$. 
If the labor supply is constrained in the first period, the multiplier $\mu_{0}$ will be zero. The higher the minimum wage and the lower the technological shock, the higher the probability of an optimal $\mu_{0}$ equal to zero. In the simulations that we have run, we have assumed that the productivity shock at $t=-1$ $\left(\theta_{-1}\right)$ always equals the steady state value. However, we have repeated the same exercise specifying different values for the minimum wage in order to have both, cases with $\mu_{0}$ equal to zero and cases with $\mu_{0}$ strictly negative.

We can distinguish two different steps followed to find the solution:

- Step 1: given a realization of the shock $\left\{\theta_{t}\right\}_{t=0}^{T}$ and an initial government indebtedness $b_{-1}$, suppose that in a given period $t, \mu_{t}=0$ and $\delta_{t} \leq 0$ (case 2). Hence, the minimum wage constraint is binding, that is, $w_{t}=w_{M I N}$. From the resource constraint (1), the first order condition with respect to government spending (17), and the minimum wage constraint, we get the optimal allocations for private consumption, public expenditure and leisure. Substituting into the first order condition with respect to leisure (16) we calculate the multiplier $\delta_{t}$ and verify if it is negative. A positive multiplier implies a contradiction. If this is the case, we should suppose that $\delta_{t}=0$ and that the minimum wage constraint is not binding (case 1). Then, the equilibrium allocations for $\left(c_{t}, g_{t}, x_{t}\right)$ are obtained from (1), (16), and (17). Performing the same exercise for the temporal sequence of shocks, we get the equilibrium paths for these three endogenous variables. Since $\mu_{t}=0$, inequality (14) is not binding. We assume that $\left(1-\tau_{t}\right)=\frac{u_{x, t}}{w_{t} u_{c t}}-\widetilde{T}$, with $\widetilde{T}>0$. Furthermore, the implementability constraint (15) has also to be fulfilled. Assuming a fixed value for $\widetilde{T}$, we compute the optimal 
allocations for $\mathrm{N}$ different realizations of the shock following the procedure described above. Next, we average across these $\mathrm{N}$ realizations to approximate the expectation in the right-hand side of the implementability constraint. If this average is different from $b_{-1}$ we change the proposed $\widetilde{T}$ and iterate until the implementability constraint is satisfied. Convergence to a negative $\widetilde{T}$ contradicts the assumption that $\mu_{t}=0$, and leads to the following step.

- Step 2: we proceed in a similar way to that presented in the previous step, but assuming that $\mu_{t}<0$. Setting a fixed value for the Lagrange multiplier $\lambda$, we consider the case 4 in which the minimum wage constraint is binding, $w_{t}=w_{M I N}$, and $\delta_{t} \leq 0$. We obtain an allocation $\left(c_{t}, x_{t}, g_{t}\right)$ that solves the resource constraint (1) and the first order conditions (16)-(18) for this particular realization of the productivity shock. ${ }^{12}$ We check if the corresponding $\delta_{t}$ is negative. If we obtain a positive multiplier, we conclude that we are not in case 4 but in case 3 , that is, $\mu_{t} \leq 0$ and $\delta_{t}=0$. Substituting into the first order conditions, we get the equilibrium allocations of the endogenous variables. Repeating this procedure with $\mathrm{N}$ different realizations of the shock, we get the $\mathrm{N}$ equilibrium paths for the endogenous variables given these shock sequences. Again, we average across the $\mathrm{N}$ realizations to approximate the expectation in the right-hand side of the implementability constraint. If this average is different from $b_{-1}$ we change the proposed $\lambda$

\footnotetext{
${ }^{12}$ Recall that we are considering the case in which the two inequality constraints in the Lagrange problem are binding. Hence, we also use these two equations in order to find the optimal allocations.
} 
and iterate until the implementability constraint is fulfilled. 


\section{References}

[1] Barro, R. (1979): "On the Determination of Public Debt", Journal of Political Economy, vol. 87, pp. 940-971.

[2] Barro, R and H. Grossman (1971): "A General Disequilibrium Model of Income and Employment", American Economic Review, vol. 61, n.1, pp. 82-93.

[3] Benassy, J.P. (1975): "Neo-Keynesian Disequilibrium in a Monetary Economy", Review of Economic Studies, vol. 42, pp. 503-523.

[4] Benassy, J.P. (1986): Macroeconomics: An Introduction to the NonWalrasian Approach. New York: Academic Press.

[5] Chari, V.V., L. Christiano and P. Kehoe (1994): "Optimal Fiscal Policy in a Business Cycle Model", Journal of Political Economy, vol. 102, pp. 617-652.

[6] Chari, V., L. Christiano and P. Kehoe (1996): "Policy Analysis in Bussines Cycle Models", in Frontiers of Bussines Cycle Research, ch. 12, ed. by T. Cooley and E. Prescott. Princeton University Press: Princeton. New Jersey.

[7] Chari, V.V. and P. Kehoe (1998): "Optimal Fiscal and Monetary Policy" Federal Reserve Bank of Minneapolis. Research Department Staff Report 251. 
[8] Christiano, L. and M. Eichenbaum (1992): "Current Real-BussinessCycle Theories and Aggregate Labor-Market Fluctuations", American Economic Review vol. 82, n. 3, pp. 431-450.

[9] Clower, R.W. (1965): "The Keynesian Counterrevolution: A Theoretical Appraisal", in The Theory of Interest Rates, ed. by F. H. Hahn and F. Brechling. London: Macmillan.

[10] Drazen, A. (1980): "Recent Developments in Macroeconomic Disequilibrium Theory", Econometrica, vol. 48, n.2 pp.283-306.

[11] Gorostiaga, A. (1999): "Should Fiscal Policy Be Different in a NonCompetitive Framework?", CEMFI, Working Paper no. 9901.

[12] Hahn, F.H.(1978): “On Non-Walrasian Equilibria", Review of Economic Studies, vol. 45 pp. 1-17.

[13] King R. (1993): "Will the New Keynesian Macroeconomics Resurrect the IS-LM Model?", Journal of Economic Perspectives, vol. 7, n. 1, pp. $67-82$.

[14] Kydland, F. and E. Prescott (1980): "Dynamic Optimal Taxation, Rational Expectations and Optimal Control", Journal of Economic Dynamics and Control, vol. 2, pp. 79-91.

[15] Lucas, R. and N. Stokey (1983): "Optimal Fiscal and Monetary Policy in an Economy without Capital", Journal of Monetary Economics, vol. 12, pp. $55-93$ 
[16] Malinvaud, E. (1977): The Theory of Unemployment Reconsidered. Oxford: Basil Blackwell.

[17] Mankiw, G. and D. Romer (1991): "Introduction", in New Keynesian Economics, vol.1, Imperfect Competition and Sticky Prices, ch.1, ed. by G. Mankiw and D. Romer. Cambridge: MIT Press.

[18] Marcet, A., T. Sargent and J. Seppälä (1996): “Optimal Taxation without State-Contingent Debt". Mimeo.

[19] Neary, J.P. and J. Stiglitz (1983): "Toward a Reconstruction of Keynesian Economics: Expectations and Constrained Equilibria", Quarterly Journal of Economics, vol. 98, Suppl., pp. 199-228.

[20] Patinkin, D. (1965): Money, Interest and Prices: An Integration of Monetary and Value Theory, 2nd edition, New York: Harper and Row.

[21] Pissarides, C. (1988): "Unemployment and Macroeconomics: An Inaugural Lecture", London School of Economics Centre for Labour Economics Discussion Paper 304.

[22] Ramsey, F. (1927): "A Contribution to the Theory of Taxation", Economic Journal, vol. 37, pp.47-61. 
Figure 1: Technological shock vs endogenous variables

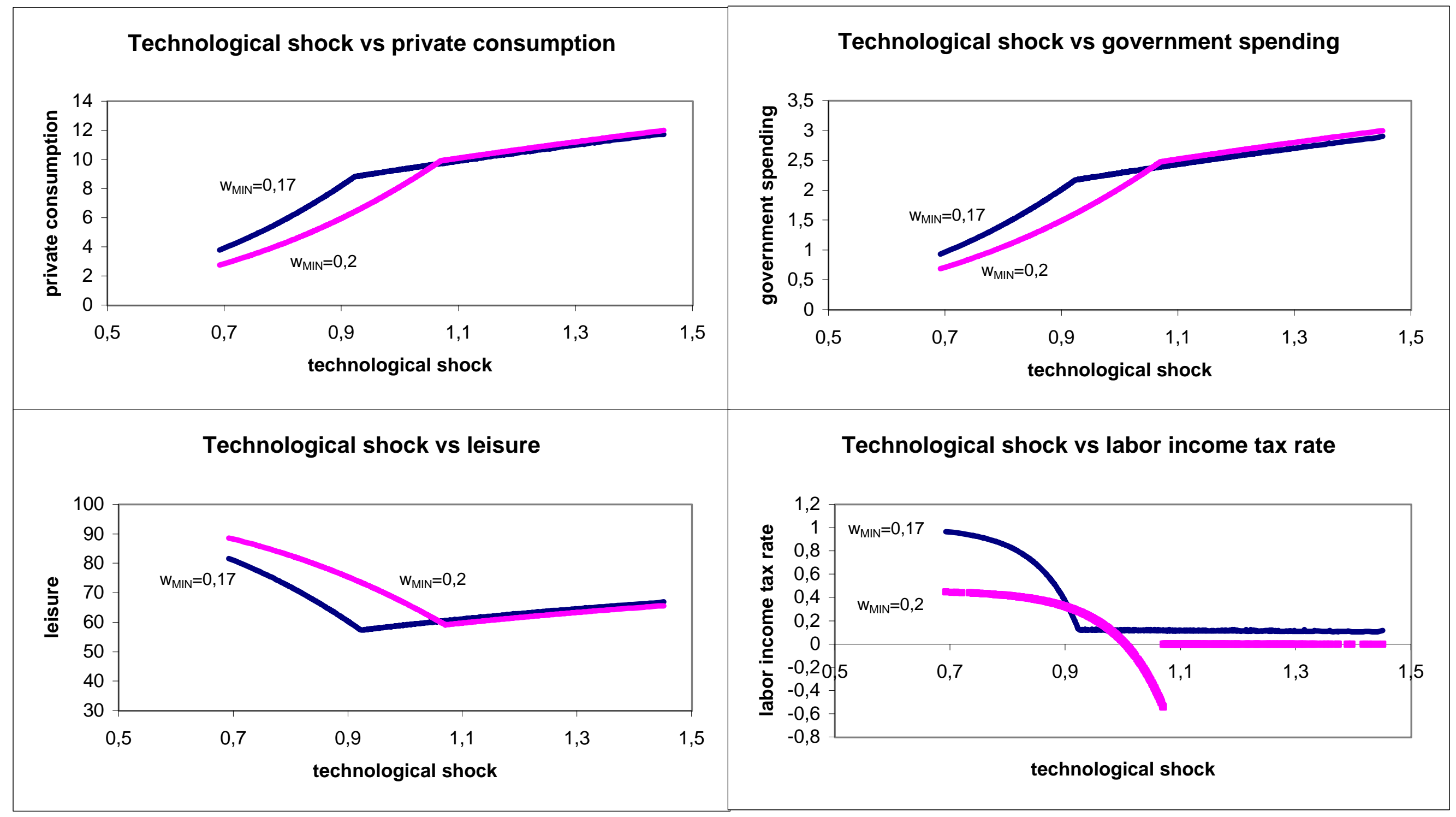


Figure 2

$\mu_{t} \neq 0$

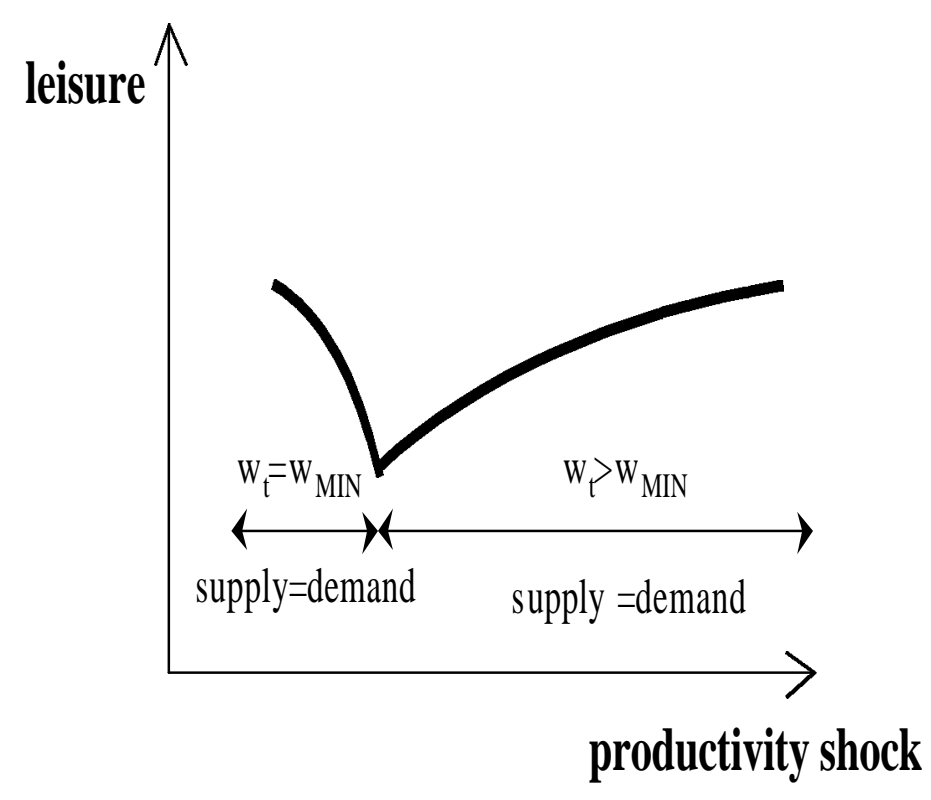

$\mu_{t}=0$

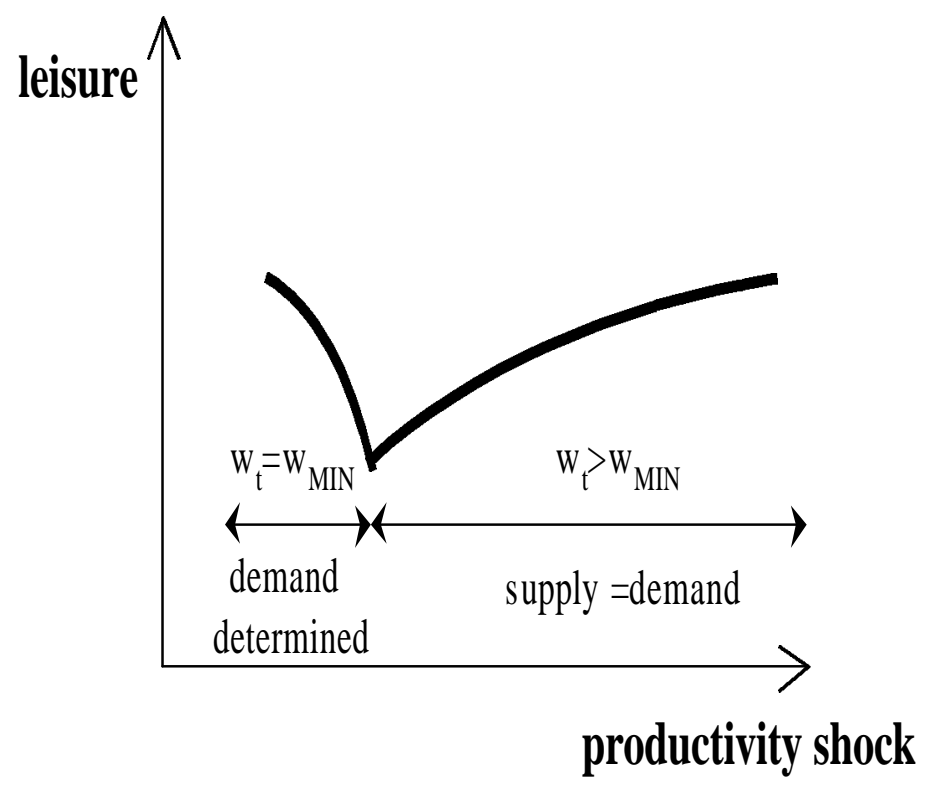

